\title{
Influência da própolis sobre os perfis leucocitário e proteico de camundongos e tempo de fechamento de feridas excisionais limpas e infectadas por Staphylococcus aureus.
}

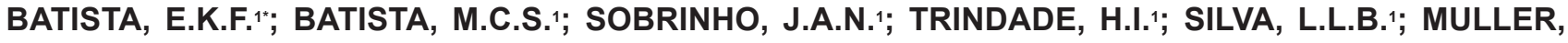 \\ J.B.B.S.'; \\ 1 Universidade Federal do Piauí/ UFPI, Centro de Ciências Agrárias, Bairro Socopo, CEP: 64049-550, Teresina, \\ Piauí. *Autor para correspondência: emanuellefrota@yahoo.com.br
}

\begin{abstract}
RESUMO: Este estudo teve como objetivo avaliar os efeitos da própolis sobre os perfis leucocitário e protéico de camundongos e sobre o tempo de fechamento de lesões de pele confeccionadas experimentalmente, limpas e infectadas com Staphylococcus aureus. No primeiro, foram utilizados 48 animais divididos em quatro grupos, sendo um tratado com solução hidroalcóolica pura e três tratados com própolis a $10 \%$, nas dosagens de $20 \mathrm{mg}, 40 \mathrm{mg} \mathrm{e} 80$ $\mathrm{mg}$ por animal de 25 gramas de peso, em única aplicação intraperitoneal. Foram coletadas amostras de sangue no segundo, $10^{\circ}, 18^{\circ}$ e $26^{\circ}$ dias após o tratamento para realização de leucograma, proteinograma e fracionamento eletroforético das proteínas. Na avaliação da atividade cicatrizante, também foram utilizados 48 camundongos divididos em seis grupos, nos quais realizou-se a confecção cirúrgica de feridas na dimensão de $1 \mathrm{~cm}^{2}$, após anestesia dissociativa. Dois grupos serviram como controle para feridas limpas e infectadas. Dois grupos de feridas infectadas por $S$. aureus e dois grupos de feridas limpas foram tratados com própolis a $5 \%$ e $10 \%$, sendo a escolha destas concentrações baseada em um estudo piloto realizado. Os resultados mostraram que o tratamento com própolis influencia o leucograma e o proteinograma, de forma dose-dependente, sendo que a maior dose utilizada desencadeou leucocitose com linfocitose e aumento de proteínas da fração gamaglobulínica, no $10^{\circ}$ dia após o início do tratamento. Também mostraram que a concentração da solução influenciou o tempo de cicatrização das feridas infectadas, ocorrendo em menor tempo no grupo tratado com a solução a $5 \%$.
\end{abstract}

Palavras-chave: própolis, cicatrização, leucograma, proteinograma.

\begin{abstract}
Influence of Propolis on leukocyte and protein profiles of mice and closing time of excisional wounds clean and infected by Staphylococcus aureus. This study aimed to evaluate the propolis effects on both the leukocyte and protein profiles of mice and on the closing time of skin lesions made experimentally, clean and infected with Staphylococcus aureus. The first 48 animals were divided into four groups, one treated with pure alcohol solution and three treated with propolis $10 \%$ at dosages of $20 \mathrm{mg}, 40 \mathrm{mg}$ and $80 \mathrm{mg}$ per $25 \mathrm{~g}$ of animal weight in an intraperitoneal single application. Blood samples in the second, and then $10^{\circ}, 18^{\circ}$ and $26^{\circ}$ days after treatment were collected in order to perform WBC, proteins and electrophoretic fractionation of proteins. Regarding the healing activity, also 48 mice divided into six groups were used, in whom surgical wounds in the size of $1 \mathrm{~cm} 2$ were purposely inflicted, after the dissociative anesthesia were applied. Two groups served as control ones, for clean and infected wounds. Two groups of S. aureus with infected wounds and two groups with clean sores were treated with $5 \%$ and $10 \%$ propolis, being this concentration choice based on a pilot study previously performed. The results showed that treatment with propolis influences leukocyte and protein concentrations in a dose- dependent manner, with the highest dose triggering leukocytosis with lymphocytosis and increasing the protein fraction of gamaglobulínica, on the 10th day after the start of treatment. It also indicated that the concentration of the solution influence the time of healing of infected wounds, since the process on the group treated with $5 \%$ solution happened faster.
\end{abstract}

Keywords: propolis, healing, WBC, proteins.

Recebido para publicação em 08/09/2012 


\section{INTRODUÇÃO}

A própolis é uma substância resinosa produzida por abelhas de diversas espécies, a partir do exsudato de plantas (árvores, flores e folhas), pólen e secreções salivares e enzimáticas, secretadas pelo metabolismo glandular desses insetos (Funari \& Ferro, 2006). Sua composição química é bastante variável e complexa, estando relacionado com a fitogeografia da região (Castro et al., 2007; Sousa et al., 2007; Buriol et al., 2009; Cabral et al., 2009). Estudos realizados em distintas espécies evidenciaram que a própolis possui diversas propriedades biológicas, como antifúngica, anti-tumoral, antibacteriana (Araújo et al., 2012; Mannani et al., 2012; Kuropatnicki et al., 2013), antiinflamatória (Moura et al., 2009), cicatrizante (Souza et al., 2009), antiulcerogênica (Barros et al., 2008), antiparasitária (Pontin et al., 2008) e antioxidante (Oldoni et al., 2011), imunoestimulatória (Sforcin et al., 2005, Missima \& Sforcin, 2008).

Mais de 300 compostos químicos já foram identificados, incluindo ácidos fenólicos, flavonóides, ésteres, diterpenos, sesquiterpenos, lignanas, aldeídos aromáticos, álcoois, aminoácidos, ácidos graxos, vitaminas e minerais terpenos (Bankova, 2005; Funari \& Ferro, 2006). Dentre esses compostos, os flavonóides são considerados os principais responsáveis pelos efeitos terapêuticos da própolis, possuindo ação antibacteriana, antiviral, antioxidante, cicatrizante, imunomoduladora, antiinflamatória, analgésica, regenerativa de cartilagens e ossos e vasodilatadora (Chen et al., 2005; Menezes, 2005; Fernandes Junior et al., 2006; Volpi \& Bergonzini, 2006; Sperança et al., 2007).

Apesar da existência de muitas preparações para o tratamento de feridas, as lesões de pele possuem grande importância clínica devido à alta frequência com que ocorrem bem como seu elevado custo no tratamento. A cicatrização de feridas pode ocorrer espontaneamente, mas quando tratada, ocorre de forma mais rápida e com melhores resultados funcionais e estéticos (Mörschbächer et al., 2011).

O arsenal terapêutico utilizado na cicatrização de feridas tem por finalidade obter uma cicatrização esteticamente correta e no menor tempo possível, no intuito de se evitarem complicações como as infecções. Dentre as terapias alternativas, os produtos naturais vêm sendo largamente utilizados, sendo a própolis um dos mais empregados dentre os produtos de origem animal (Rocha \& Reis, 2005).

Devido às suas propriedades terapêuticas, a própolis tem sido amplamente utilizada para o tratamento de lesões cutâneas, reduzindo o tempo de cicatrização, acelerando o processo de contração das feridas e a reparação de tecidual (Ramos \&
Miranda, 2007). A própolis favorece a cicatrização atuando na regeneração e granulação dos tecidos, pois induz à reepitelização e estimula a migração de queratinócitos (Barbosa et al., 2009; Moura et al., 2011; Pinto et al., 2011).

Diversos autores afirmam que a própolis é mais eficaz contra bactérias Gram positivas e tem atividade limitada contra bactérias Gram negativas (Garcia et al., 2004; Orsi et al., 2005; Lu et al., 2005; Marcucci et al., 2001; Rezende et al., 2006; Packer \& Luz, 2007). Possui ação comprovada contra Staphylococcus aureus e S. epidermidis, e age sinergicamente com drogas antibióticas, principalmente inibidores da síntese protéica bacteriana (Fernandes Junior et al., 2005; Liberato et al., 2010). A atividade antimicrobiana da própolis deve-se principalmente à flavonona pinocembrina, ao flavonol galagina e ao éster feniletil do ácido caféico, que atuam inibindo a RNA-polimerase bacteriana (Uzel et al., 2005), e aos flavonóides, ácido caféico, ácido benzóico, ácido cinâmico, que danificam a membrana ou parede celular do microorganismo causando danos funcionais e estruturais (Scazzocchio et al., 2006).

Em face da multiplicidade de propriedades atribuídas à própolis e de algumas controvérsias oriundas de alguns estudos, realizouse este trabalho com o objetivo de avaliar os seus efeitos sobre o quadro leucocitário e as proteínas plasmáticas de camundongos e também sobre a cicatrização de feridas limpas e infectadas por $S$. aureus, nesta mesma espécie animal.

\section{MATERIAL E MÉTODOS \\ Animais}

Foram utilizados 96 camundongos (Mus musculus) de ambos os sexos, entre dois e três meses de idade, fornecidos pelo biotério do Centro de Ciências Agrárias da Universidade Federal do Piauí. Os animais foram mantidos sob condições controladas de temperatura $\left(25 \pm 2{ }^{\circ} \mathrm{C}\right)$ e ciclo de claro/escuro de $12 \mathrm{~h}$, com livre acesso a água e ração tipo "pellets" (Presence nutrição animal). O experimento recebeu parecer favorável do Comitê de Ética em Experimentos com Animais da UFPI (CEEA-UFPI) sob o nº 095/2010.

\section{Própolis utilizada}

O extrato hidroalcoólico de própolis utilizado foi adquirido da empresa Apis Flora Industrial e Comercial LTDA, localizada em Ribeirão Preto São Paulo.

A solução hidroalcoólica usada como veiculo foi preparada com álcool etílico PA e água destilada na proporção de 1:1. 


\section{Delineamento experimental}

Estudo da influência da própolis sobre os perfis leucocitário e proteico

Para a avaliação dos perfis leucocitário e protéico, foram utilizados 48 camundongos, divididos em quatro grupos de 12 , os quais foram submetidos a tratamentos diferenciados, conforme descrito na Tabela 1.

Amostras de sangue de cada animal foram coletadas em tubos com solução anticoagulante (solução de EDTA-sódico), diretamente do plexo retro orbital. O sangue foi coletado no segundo, $10^{\circ}, 18^{\circ}$ e $26^{\circ}$ dias após a administração das soluções, de acordo com a Tabela 1. A seguir foram realizados leucogramas, analise das proteínas plasmáticas totais e fracionamento de proteínas por eletroforese, conforme os procedimentos citados por Sousa et al. (1993a) e Sousa et al. (1993b). O leucograma foi realizado pelo método tradicional do hemacitômetro de Neubauer, com leitura em lâminas coradas por corante panótico; o proteinograma por espectrofotometria, usando-se kits comerciais (Lab-Test) e o fracionamento das proteínas foi feito por eletroforese em acetato-celulose (Sousa et al., 1993b).

\section{Estudo da influência da própolis sobre a cicatrização}

Para a avaliação do efeito da própolis sobre o tempo necessário para o fechamento de feridas excisionais, foram utilizados 48 camundongos divididos em seis grupos (Tabela 2). As feridas foram produzidas cirurgicamente, utilizando-se anestesia dissociativa pela associação de cetamina (140 mg/ $\mathrm{Kg})$ e xilazina $(80 \mathrm{mg} / \mathrm{Kg})$, via subcutânea. Após a anestesia dos animais, selecionou-se a região dorso-lateral direita, realizando-se tricotomia e subsequente demarcação da área de uma ferida por animal, usando-se um molde de esparadrapo medindo $1 \mathrm{~cm}^{2}$. Em seguida utilizou-se um bisturi e uma pinça para a confecção cirúrgica das feridas retirando-se a pele e tecido subcutâneo, de modo que em cada animal foi confeccionada uma lesão de pele no tamanho padronizado de um centímetro, na região dorso-lateral direita (Vitorino Filho et al., 2007).

Os animais foram tratados topicamente, duas vezes por dia, ate sua completa cicatrização, utilizando-se um dispositivo conta-gotas, de forma a preencher a superfície da lesão.

Nos grupos G-2, G-4 e G-6 procederam-se a infecção das feridas com Staphilococcus aureus coagulase e catalase positivas, imediatamente após a cirurgia e as doze, vinte e quatro e trinta e seis horas depois da confecção das feridas.

Para detectar a presença de microorganismos, 24 horas após a ultima aplicação da cultura de $S$. aureus, foram preparadas lâminas, coradas pelo método de Gram, com material colhido das feridas. O material colhido também foi semeado em tubos de ensaio contendo caldo nutriente. Os tubos foram incubados em estufa bacteriológica a $37^{\circ} \mathrm{C}$.

Após constatada a infecção em todos os animais dos grupos experimentalmente infectados (G-2, G-4 e G-6), iniciou-se o tratamento das

TABELA 1. Delineamento experimental para avaliação dos perfis leucocitário e proteico no sangue de camundongos Mus musculus, após administração intraperitoneal, em dose única, de solução hidroalcoólica de própolis a $10 \%$.

\begin{tabular}{ccc}
\hline Grupo & Tratamento & Quantidade de própolis/animal \\
\hline G-1 & Solução Hidroalcoólica pura (sem própolis) & - \\
G-2 & Própolis em Solução Hidroalcoólica a 10\% & $20 \mathrm{mg}(0,2 \mathrm{~mL})$ \\
G-3 & Própolis em Solução Hidroalcoólica a 10\% & $40 \mathrm{mg}(0,4 \mathrm{~mL})$ \\
G-4 & Própolis em Solução Hidroalcoólica a 10\% & $80 \mathrm{mg}(0,8 \mathrm{~mL})$ \\
\hline
\end{tabular}

TABELA 2. Delineamento experimental para determinação do tempo de cicatrização de feridas excisionais limpas ou infectadas com Staphilococcus aureus, na pele de camundongos, após aplicação tópica, duas vezes ao dia, de uma solução hidroalcoólica de própolis

\begin{tabular}{cccc}
\hline \multirow{2}{*}{ Grupo } & Tratamento & \multicolumn{2}{c}{ Tipo de ferida } \\
\cline { 3 - 4 } & Solução Hidroalcoólica pura & Não infectada & Infectada \\
\hline G-1 & Solução Hidroalcoólica pura & & $\mathrm{X}$ \\
G-2 & Própolis em Solução Hidroalcoólica a 5\% & $\mathrm{N}$ & \\
G-3 & Própolis em Solução Hidroalcoólica a 5\% & & $\mathrm{X}$ \\
G-4 & Própolis em Solução Hidroalcoólica a 10\% & $\mathrm{X}$ \\
G-5 & Própolis em Solução Hidroalcoólica a 10\% & & $\mathrm{X}$ \\
G-6 & & & \\
\hline
\end{tabular}

Rev. Bras. PI. Med., Campinas, v.17, n.3, p.413-419, 2015. 
feridas em todos os grupos. Foram testadas concentrações mais baixas (5\%) do que as utilizadas no experimento anterior, com base em um estudo piloto, realizado para ajuste da técnica.

\section{Analise estatística}

Os dados obtidos foram submetidos a analise de variância pelo teste de "F" de Fisher, e o calculo da diferença mínima significativa e comparação de medias pelo teste de Tukey com nível de significância $p<0,05$.

\section{RESULTADOS E DISCUSSÃO Estudo da influência da própolis sobre os perfis leucocitário e proteico \\ Os resultados das observações acerca} do papel da própolis nas respostas leucocitárias e protéicas de murinos permitiram observar que esta substancia desencadeou leucocitose, com aumento do numero de linfócitos, além de modificar o perfil proteico, elevando a fração gamaglobulina (hipergamaglobulinemia). Esses efeitos podem variar em função da posologia administrada. As contagens global e diferencial de leucócitos estão sumarizadas na Tabela 3 .

A Tabela 3 mostra que, no $10^{\circ}$ dia após o tratamento (DAT), o grupo tratado com a maior dose (G4) desenvolveu um numero de leucócitos significativamente diferente dos grupos controle (G1) e tratado com menor dose (G2). Este aumento de leucócitos foi um reflexo da elevação no número de linfócitos, cujos valores relativos também apresentaram diferença significativa em relação a G1 e G2. Orsolic \& Basic (2003) relataram que derivados de própolis solúveis em água apresentaram propriedades imunoestimulantes de linfócitos e macrófagos em ratos. A proliferação de linfócitos pode ser atribuída a atividade imunoestimulante dos compostos fenólicos da própolis (Fischer, 2008).

Arauco et al. (2006) ao adicionarem extrato hidroalcoólico de própolis na ração de girinos de rã-touro, observaram uma influência significativa na porcentagem de monócitos no sangue periférico desses animais, apresentando possivelmente efeito imunoestimulante nas doses mais baixas $(0,2$ e 0,5 $\%)$.

As proteínas representam a base estrutural das células, tecidos e órgãos, funcionando como catalisadores enzimáticos nas reações bioquímicas, carreadores de constituintes plasmáticos e participam da defesa do organismo como anticorpos. Devido sua importância biológica, a avaliação dos níveis séricos de proteínas totais e suas frações, representa um importante auxilio na avaliação geral de um individuo (Ferraz et al., 2011).

O fracionamento eletroforético das proteínas plasmáticas dos animais tratados com própolis, sumarizado na Tabela 4, revelou que houve diferenças significativas no teor de gamaglobulinas apenas nos animais que receberam a maior dose, no décimo dia após o início do tratamento e que esta fração protéica retornou aos valores basais, a partir daí. É provável que o esquema de administração (quantidade usada e repetições da administração) seja um parâmetro determinante nos resultados,

TABELA 3. Contagens global e diferencial de leucócitos de camundongos tratados com diferentes doses de solução hidroalcoólica de própolis, via intraperitoneal, em única aplicação

\begin{tabular}{|c|c|c|c|c|c|c|c|}
\hline \multirow{2}{*}{ DAT } & \multirow{2}{*}{ Grupos (doses) } & \multirow{2}{*}{$\begin{array}{l}\text { Leucócitos } / \mathrm{mm}^{3} \text { de sangue } \\
\text { (média) }\end{array}$} & \multicolumn{5}{|c|}{ Leucometria diferencial (\%médio) } \\
\hline & & & Nt. & Eos. & Bas. & Linf. & Mon. \\
\hline \multirow[t]{4}{*}{$2^{\circ}$} & G1 (zero) & $4.533 \mathrm{a}$ & $37 a$ & $01 \mathrm{a}$ & $00 \mathrm{a}$ & $60 a$ & $02 \mathrm{a}$ \\
\hline & G2 (20mg) & $4.500 \mathrm{a}$ & $38 a$ & $02 a$ & $00 \mathrm{a}$ & 56 a & $04 \mathrm{a}$ \\
\hline & G3 (40mg) & $4.800 \mathrm{a}$ & 37 a & $00 \mathrm{a}$ & $00 \mathrm{a}$ & 60 a & 03 a \\
\hline & G4 (80mg) & $6.433 \mathrm{a}$ & $36 a$ & $01 \mathrm{a}$ & $00 \mathrm{a}$ & $61 \mathrm{a}$ & $02 \mathrm{a}$ \\
\hline \multirow[t]{4}{*}{$10^{\circ}$} & G1 (zero) & $3.366 \mathrm{a}$ & $32 \mathrm{a}$ & $01 \mathrm{a}$ & 00 a & $64 a$ & $03 a$ \\
\hline & G2 (20mg) & $4.533 \mathrm{a}$ & 34 a & $02 \mathrm{a}$ & 00 a & $60 \mathrm{a}$ & $04 \mathrm{a}$ \\
\hline & G3 (40mg) & $6.000 \mathrm{ab}$ & $27 a$ & $01 \mathrm{a}$ & $00 \mathrm{a}$ & $71 a b$ & $01 \mathrm{a}$ \\
\hline & G4 (80mg) & $7.900 \quad b$ & $20 a$ & $00 \mathrm{a}$ & $00 \mathrm{a}$ & $80 \mathrm{~b}$ & $00 \mathrm{a}$ \\
\hline \multirow[t]{4}{*}{$18^{\circ}$} & G1 (zero) & $4.600 \mathrm{a}$ & $35 a$ & $00 \mathrm{a}$ & 00 a & $64 a$ & $01 \mathrm{a}$ \\
\hline & G2 (20mg) & $4.700 \mathrm{a}$ & $37 a$ & $01 \mathrm{a}$ & $00 \mathrm{a}$ & $62 \mathrm{a}$ & $00 \mathrm{a}$ \\
\hline & G3 (40mg) & $5.200 \mathrm{a}$ & $32 a$ & $00 \mathrm{a}$ & $00 \mathrm{a}$ & $65 a$ & $03 a$ \\
\hline & G4 (80mg) & $5.900 \mathrm{a}$ & $36 a$ & $00 \mathrm{a}$ & $00 \mathrm{a}$ & $62 \mathrm{a}$ & $02 \mathrm{a}$ \\
\hline \multirow[t]{4}{*}{$26^{\circ}$} & G1 (zero) & $3.266 \mathrm{a}$ & $33 a$ & $02 a$ & $00 \mathrm{a}$ & $62 \mathrm{a}$ & $03 a$ \\
\hline & G2 (20mg) & $3.766 \mathrm{a}$ & $38 a$ & $00 \mathrm{a}$ & $00 \mathrm{a}$ & $60 \mathrm{a}$ & $02 \mathrm{a}$ \\
\hline & G3 (40mg) & $4.533 a$ & $33 a$ & $01 a$ & $00 \mathrm{a}$ & $65 a$ & $01 \mathrm{a}$ \\
\hline & G4 (80mg) & $5.233 \mathrm{a}$ & $26 a$ & $01 \mathrm{a}$ & $00 \mathrm{a}$ & $70 \mathrm{a}$ & $03 a$ \\
\hline
\end{tabular}

Nota: DAT: dias após o tratamento; Nt: neutrófilos totais; Eos: eosinófilos; Bas: basófilos; Linf: linfócitos; Mon: monócitos. Letras diferentes na mesma coluna indicam diferença significativa $(P<0,05)$. 
porém a influência da própolis nas respostas celular e humoral pode ser constatada mediante a observação dos resultados deste estudo.

\section{Estudo da influência da própolis sobre a cicatrização}

Após a confecção das feridas há um aumento de sua área em relação ao molde, isso acontece porque as bordas da lesão sofrem retração centrífuga devido à tensão elástica da pele circunjacente, perda de aderência à fáscia profunda, e mobilidade da pele do animal. Entretanto, essa variação não interferiu no tempo de cicatrização das feridas analisadas neste trabalho, pois o cálculo da contração depende da diferença entre as áreas inicial e a encontrada no dia em que se quer avaliar a contração, sendo feito individualmente e não com as médias (Cross et al., 1995; Teo \& Naylor, 1995).

O estudo macroscópico sobre o efeito da própolis na cicatrização de feridas não infectadas e infectadas por $S$. aureus, permitiu observar diferenças entre os tratamentos adotados. As feridas dos animais infectados, tratados com o veiculo (G-2) levaram maior tempo $(p<0,05)$ para a cicatrização em relação às feridas dos animais dos grupos $\mathrm{G}-1$, G-3 e G-4, conforme mostra Tabela 5.

A própolis em solução hidroalcoólica a $5 \%$ mostrou-se mais efetiva no tempo de fechamento das lesões, tanto em feridas não infectadas, quanto nas infectadas por $S$. aureus, do que em solução hidroalcoólica a 10\%. Peruchi et al. (2001), ao compararem a cicatrização de lesões subcutâneas induzidas em ratos a partir do uso de solução alcoólica de própolis a $10 \%$ e $30 \%$, constataram que ambas estimularam a reparação tecidual, ocorrendo uma acentuada neo-formação vascular, seguida de rápida regeneração do tecido, embora o resultado das lesões tratadas com solução a $30 \%$ fosse mais lento. Rahal et al. (2003) ao avaliarem a influencia do mel e da própolis na cicatrização de feridas por segunda intenção, observaram que estes tratamentos proporcionaram uma resposta inflamatória menos intensa quando comparado ao controle, porem a própolis estimulou uma

TABELA 4. Distribuição eletroforética das proteínas plasmáticas de camundongos tratados com diferentes doses de própolis, via intraperitoneal, em única aplicação

\begin{tabular}{ccccccc}
\hline \multirow{2}{*}{ DAT } & \multirow{2}{*}{ Grupos (doses) } & \multirow{2}{*}{$\begin{array}{c}\boldsymbol{N}^{\circ} \text { de animais } \\
\text { analisados }\end{array}$} & \multirow{2}{*}{ Albumina (\% medio) } & \multicolumn{3}{c}{ Globulinas (\%médio) } \\
\cline { 3 - 7 } $2^{\circ}$ & G1 (zero) & 4 & $55,0 \mathrm{a}$ & $14,0 \mathrm{a}$ & $16,8 \mathrm{a}$ & $14,2 \mathrm{a}$ \\
& G2 (20mg) & 4 & $57,6 \mathrm{a}$ & $14,0 \mathrm{a}$ & $14,0 \mathrm{a}$ & $13,8 \mathrm{a}$ \\
& G3 (40mg) & 4 & $55,5 \mathrm{a}$ & $14,6 \mathrm{a}$ & $14,2 \mathrm{a}$ & $15,7 \mathrm{a}$ \\
$1^{\circ}$ & G4 (80mg) & 4 & $50,2 \mathrm{a}$ & $14,1 \mathrm{a}$ & $17,5 \mathrm{a}$ & $18,2 \mathrm{a}$ \\
& G1 (zero) & 4 & $54,7 \mathrm{a}$ & $15,0 \mathrm{a}$ & $16,8 \mathrm{a}$ & $13,5 \mathrm{a}$ \\
& G2 (20mg) & 4 & $58,3 \mathrm{a}$ & $12,1 \mathrm{a}$ & $14,6 \mathrm{a}$ & $15,0 \mathrm{a}$ \\
& G3 (40mg) & 4 & $55,5 \mathrm{a}$ & $12,0 \mathrm{a}$ & $14,5 \mathrm{a}$ & $18,0 \mathrm{ab}$ \\
$8^{\circ}$ & G4 (80mg) & 4 & $46,0 \mathrm{a}$ & $13,9 \mathrm{a}$ & $16,5 \mathrm{a}$ & $23,6 \mathrm{~b}$ \\
& G1 (zero) & 4 & $53,5 \mathrm{a}$ & $17,0 \mathrm{a}$ & $16,3 \mathrm{a}$ & $13,2 \mathrm{a}$ \\
& G2 (20mg) & 4 & $50,5 \mathrm{a}$ & $15,9 \mathrm{a}$ & $17,7 \mathrm{a}$ & $15,9 \mathrm{a}$ \\
& G3 (40mg) & 4 & $53,5 \mathrm{a}$ & $12,2 \mathrm{a}$ & $19,2 \mathrm{a}$ & $16,1 \mathrm{a}$ \\
& G4 (80mg) & 4 & $49,8 \mathrm{a}$ & $15,2 \mathrm{a}$ & $18,0 \mathrm{a}$ & $17,0 \mathrm{a}$ \\
\hline
\end{tabular}

DAT: dias após o tratamento. * $=$ valores alfa-1 e alfa- 2 .

Letras diferentes na mesma coluna indicam diferença significativa $(P<0,05)$.

TABELA 5. Tempo de cicatrização em dias, de feridas excisionais limpas ou infectadas com Staphilococcus aureus, na pele de camundongos, após aplicação tópica, duas vezes ao dia, de uma solução hidroalcoólica de própolis

\begin{tabular}{lccccc}
\hline \multirow{2}{*}{ Grupo (Tratamento) } & \multicolumn{2}{c}{ Feridas } & \multicolumn{3}{c}{ Tempo de cicatrização } \\
\cline { 2 - 6 } & Não infectada & Infectada & Media & Desvio padrão & C.V. \\
\hline G1 (Sol. Hidroalcoólica pura) & $X$ & & $11,2 \mathrm{a}$ & 2,25 & 0,20 \\
G2 (Sol. Hidroalcoólica pura) & & $X$ & $14,6 \mathrm{~b}$ & 0,74 & 0,05 \\
G3 (própolis a 5\%) & $\mathrm{X}$ & & $10,4 \mathrm{a}$ & 1,60 & 0,15 \\
G4 (própolis a 5\%) & & $\mathrm{X}$ & $11,1 \mathrm{a}$ & 1,96 & 0,18 \\
G5 (própolis a 10\%) & $\mathrm{X}$ & & $12,0 \mathrm{ab}$ & 2,07 & 0,17 \\
G6 (própolis a 10\%) & & $\mathrm{X}$ & $13,0 \mathrm{ab}$ & 2,14 & 0,16 \\
\hline
\end{tabular}

Numero de animais por grupo: 8; Médias seguidas da mesma letra na coluna, não diferem entre si pelo teste de Tukey, ao nível de $5 \%$ de probabilidade. 
reepitelização mais precoce.

Neste experimento, as soluções foram preparadas em veiculo hidroetanólico, a partir da tintura de própolis que já contem álcool. A solução a $10 \%$ atingiu um conteúdo maior de álcool e isso pode contribuir para explicar a diferença observada em seus efeitos. O tipo de solvente empregado, além do protocolo adotado, poderá resultar em maior ou menor eficiência de extração de determinadas substâncias como os compostos fenólicos, nos quais se concentra a maior parte da atividade farmacológica da própolis (Fischer, 2008).

Barbosa et al. (2009) afirmaram que a concentração de etanol utilizada no preparo de extratos de própolis, bem como o modo como estes extratos são realizados, influenciam a concentração de flavonóides e, consequentemente, sua ação farmacológica, entre elas a atividade antimicrobiana. Também observaram que o uso da própolis em feridas diminuiu o tempo de cicatrização, e acelera o processo de regeneração tissular, oferecendo recuperação dos tecidos lesionados por sua ação antimicrobiana, anti-inflamatória, analgésica e de neo-angiogênese (Barbosa et al., 2009).

Lopes-Rocha et al. (2012) ao estudarem o efeito do extrato etanólico da própolis sobre a cicatrização de feridas na mucosa oral de hamsters, observaram que os animais tratados com própolis exibiram uma menor área de ulceração, redução da resposta inflamatória, formação inicial do tecido de granulação, e epitelização mais rápida quando comparados com os demais tratamentos.

A partir dos resultados deste trabalho conclui-se que o tratamento intraperitoneal de camundongos com própolis, em solução hidroetanólica, produz modificações no leucograma e traçado eletroforético das proteínas plasmáticas, cujo grau é influenciado pela posologia. A solução de própolis à $10 \%$, administrada oralmente na dose de $80 \mathrm{mg}$ por animal, desencadeia leucocitose, com linfocitose relativa e elevação dos teores de gamaglobulina, no décimo dia após o tratamento. O efeito da própolis em solução hidroetanólica, aplicada topicamente, sobre a cicatrização de feridas de camundongos experimentalmente infectadas por $S$. aureus é influenciado pela concentração utilizada, havendo redução no tempo de cicatrização dessas feridas após aplicação de solução hidroetanólica de própolis a $5 \%$, duas vezes ao dia. Entretanto, a aplicação tópica de solução hidroetanólica de própolis a $5 \%$ e a $10 \%$, duas vezes ao dia, não reduz o tempo necessário para a cicatrização de feridas limpas.

\section{REFERENCIAS}

ARAUCO, L.R.R. et al. Efeito do extrato hidroalcoólico de própolis na composição leucocitária do sangue de girinos de rã-touro (Rana catesbeiana). Kempffiana, vol. 2, n.1, p.35-44, 2006.

ARAÚJO, M.A.R. et al. Mechanisms of action underlying the anti-inflammatory and immunomodulatory effects of propolis: a brief review. Revista Brasileira de Farmacognosia, vol. 22, n. 1, p. 208-219, 2012.

BANKOVA, V. Chemical diversity of propolis and the problem of standardization. Journal of Ethnopharmacology, vol. 100, n. 1-2, p. 114-117, 2005.

BARBOSA, M.H. et al. Ação terapêutica da própolis em lesões cutâneas. Acta Paulista de Enfermagem, vol. 22, n.3, p.318-22, 2009.

BARROS, M.P. et al. Evaluation of antiulcer activity of the main phenolic acids found in Brazilian green propolis. Journal of Ethnopharmacology, vol. 120, n. 3, p. 372-377. 2008.

BURIOL, L. et al. Composição química e atividade biológica de extrato oleoso de própolis: uma alternativa ao extrato etanólico. Química Nova, vol. 32, n. 2, p. 296-302, 2009.

CABRAL, I.S.R., et al. Composição fenólica, atividade antibacteriana e antioxidante da própolis vermelha brasileira. Química Nova, vol. 32, n.6, p.1523-1527, 2009.

CASTRO, M.L., et al. Própolis do sudeste e nordeste do Brasil: influência da sazonalidade na atividade antibacteriana e composição fenólica. Química Nova, vol. 30, n. 7, p. 1512-1516, 2007.

CHEN, M. et al. Caffeic acid phenethyl ester decreases acute pneumonitis after irradiation in vitro and in vivo. BMC Cancer, vol. 5, n.158, p.1-9, 2005.

CROSS, S.E. et al. An experimental model to investigate the dymamics of wound contraction. British Journal of Plastic Sugery, vol. 48, n. 4, p. 189-197, 1995.

FERNANDES JUNIOR, A. et al. Atividade antimicrobiana de própolis de Apis mellifera obtidas em três regiões do Brasil. Ciência Rural, vol. 36, n. 1, p. 294-297, 2006.

FERNANDES JÚNIOR, A. et al. Propolis: antiStaphylococcus aureus activity and synergism with antimicrobial drugs. Memórias do Instituto Oswaldo Cruz, vol. 100, n. 5, p. 563-566, 2005.

FERRAZ, M.C. et al. Ação da própolis sobre as proteínas do soro e aspectos hematológicos em Callitrhix sp. submetidos ao estresse em cativeiro. Veterinária e Zootecnia, vol.18, n.1, p.70-80, 2011.

FISCHER, G. et al. Imunomodulação pela própolis. Arquivos do Instituto Biológico, vol.75, n. 2, p. 247253, 2008.

FUNARI, C.S.; FERRO, V.O. Análise de própolis. Ciência e Tecnologia de Alimentos, vol. 26, n. 1, p. 171-178, 2006.

GARCIA, R.C. et al. Efeito do extrato alcoólico de própolis sobre a Pasteurella multocida in vitro e em coelhos. Acta Scientiarum Animal Sciences, vol.26, n.1, p.6977, 2004.

KUROPATNICKI, S.K. et al. Historical aspects of propolis research in modern times. Evidence-Based Complementary and Alternative Medicine, vol. 2013, n. 1, p. 1-11, 2013.

LIBERATO, M.C.T.C. et al. Atividade antimicrobiana dos extratos de própolis de Alto Santo, Mombaça, Crato e Beberibe - Ceará. In: CONGRESSO BRASILEIRO DE QUÍMICA, 50.․ 2010, Cuiabá - MT. 
LOPES-ROCHA, R. et al. Effect of tropical própolis and dexamethasone on the healing of oral surgical wounds. Wound Healing Southerm Africa, vol. 25, n. 1, p. 2530, 2012.

LU, L. et al. Antibacterial activity of propolis against Staphylococcus aureus. International Journal of Food Microbiology, vol. 102, n. 2, p. 213-220, 2005.

MANNANI, R.I. et al. In vitro antifungal activity of Iranian propolis against Microsporum canis, M. gypseum and $M$. nanum. Journal of Biologically Active Products from Nature, vol. 2, n. 2, p. 119-123, 2012.

MARCUCCI, M.C. et al. Phenolic compounds from Brazilian propolis with pharmacological activities. Journal of Ethnopharmacology, vol. 74, n. 2, p. 105-112, 2001.

MENEZES, H. Própolis: uma revisão dos recentes estudos de suas propriedades farmacológicas. Arquivos do Instituto Biológico, vol.72, n.3, p.405-411, 2005.

MISSIMA, F.; SFORCIN, J.M. Green Brazilian propolis action on macrophages and lymphoid organs of chronically stressed mice. Evidence-based Complementary and Alternative Medicine, vol. 5, n. 1, p. 71-75, 2008.

MÖRSCHBÄCHER, P.D. et al. Uso de membrana biológica de hemicelulose (VELODERM®) e pomada de calêndula (Calendula officinalis) como adjuvante na cicatrização músculo-cutânea em um cão. Veterinária e Zootecnia, vol.18, n.3, p.366-370, 2011.

MOURA, S.A.L. et al. Aqueous extract of Brazilian green propolis: primary components, evaluation of inflammation and wound healing by using subcutaneous implanted sponges. Evidence Based Complementary Alternative Medicine, vol. 2011, ID 748283, p. 1-8, 2009.

MOURA, S.A.L. et al. Brazilian green propolis inhibits inflammatory angiogenesis in a murine sponge model. Evidence-Based Complementary and Alternative Medicine, vol. 2011, ID 182703, p. 1-7, 2011.

OLDONI, T.L.C. et al. Isolation and analysis of bioactive isoflavonoids and chalcone from a new type of Brazilian propolis. Separation and Purification Technology, vol. 77, n. 2, p. 208-213, 2011.

ORSI, R.O. et al. Susceptibility profile of Salmonellaagainst the antibacterial activity of propolis produced in two regions of Brazil. Journal of Venomous Animals and Toxins including Tropical Diseases, vol. 11, n. 2, p. 109-116, 2005.

ORSOLIC, N.; BASIC. I. Immunomodulation by watersoluble derivative of propolis: a factor of antitumor reactivity. Journal of Enthnopharmacology, vol. 84, n.2, p.265-273. 2003.

PACKER, J. F.; LUZ, M. M. S. Método para avaliação e pesquisa da atividade antimicrobiana de produtos de origem natural. Revista Brasileira de Farmacognosia, v.17, n.1, p. 102-107, 2007.

PERUCHI, C.M.S. et al. Efecto del propóleos en la cicatrización de lesiones subcutáneas inducidas en el dorso de ratones: estúdio histológico. Revista de la Facultad de Odontología de la Universidad de Chile, vol.19, n.2, p.23-34, 2001.

PINTO, L.deM.A., et al. Propriedades, usos e aplicações da própolis. Revista Eletrônica de Farmácia. vol. 8, n.3, p.76-100, 2011.

PONTIN, K. et al. In vitro and in vivo antileishmanial activities of a Brazilian green propolis extract. Parasitology
Research, vol. 103, n. 3, p. 487-492, 2008.

RAHAL, S.C. et al. Utilização de própolis ou mel no tratamento de feridas limpas induzidas em ratos. Archives of Veterinary Science, vol.8, n.1, p.61-67, 2003.

RAMOS, A.F.N.; MIRANDA, J.L. de. Propolis: a review of its anti-inflammatory and healing actions. Journal of Venomous Animals and Toxins Including Tropical Diseases, vol. 13, n. 4, p. 697-700, 2007.

REZENDE, G.P.S.R. et al. Antimicrobial activity of two Brazilian commercial própolis extracts. Brazilian Journal of Oral Sciences, vol. 5, n. 16, p. 967-970, 2006.

ROCHA, C.B.J.; REIS, N,S.dos. Estudo comparativo do efeito de glicosaminaglicanas ácidas sulfatada (Hirudóid®) e não-Sulfatada (ácido hialurônico) e da própolis sobre a cicatrização da pele de ratos albinos. Revista Científica da Universidade de Franca, vol. 5, n. 1/6, p. 101-109, 2005.

SCAZZOCCHIO F, et al. Multifactorial aspects of antimicrobial activity of propolis. Microbiological Research, v. 161, n. 4, p. 327-333, 2006.

SFORCIN, J.M.; ORSI, R.O.; BANKOVA, V. Effect of propolis, some isolated compounds and its source plant on antibody production. Journal of Ethnopharmacology, v. 98, n.3, p. 301-305, 2005.

SOUSA, J.P.B. et al. Perfis físico químico e cromatográfico de amostras de própolis produzidas nas microrregiões de Franca (SP) e Passos (MG). Revista Brasileira de Farmacognosia, vol. 17, n. 1, p. 85-93, 2007.

SOUSA, M.C.B.B. et al. Efeito do tratamento com C. parvu, inativado sobre os teores de proteínas plasmáticas de camundongos. Revista Brasileira de Farmácia, vol. 74, n. 4, p. 82-84, 1993b.

SOUSA, M.C.B.B. et al. Efeito do tratamento com Corynebacterium parvu, inativado sobre o perfil leucocitário de camundongos. Revista Brasileira de Farmácia, vol. 74, n. 3, p. 63-66, 1993a.

SOUZA, A.P.B. et al. Efetividade da Delphinum staphysagria $6 \mathrm{cH}$ e $30 \mathrm{cH}$ em ensaios biológicos para cicatrização. Brazilian Homeopathic Journal, vol. 11, n. 1, p. 13-14, 2009.

SPERANÇA, P.A. et al. Verificação da atividade antimicrobiana de soluções à base de própolis, sobre microbiota oriunda de bolsas periodontais - Estudo in vitro. Periodontia, vol. 17, n. 4. p. 54-59, 2007.

TEO, T.C.; NAYLOR, I.L. Modifications to the rate of wound contration by allopurinol. British Journal of Plastic Surgery, vol. 48, n. 4, p. 198-202, 1995.

UZEL, A. et al., Chemical compositions and antimicrobial activities of four different anatolian propolis samples. Microbiological Research, vol. 160, n. 2, p. 189-195, 2005.

VITORINO FILHO, R.N.L. et al. Avaliação do uso de pomada à base de semente de jaqueira (Artocarpus heterophyllus Lam) na terapêutica tópica de feridas. Revista de Ciências Farmacêuticas Básica e Aplicada, vol. 28, n. 3, p. 279-286, 2007.

VOLPI, N.; BERGONZINI, G. Analysis of $\mathrm{fl}$ avonoids from propolis by on-line HPLC-electrospray mass spectrometry. Journal of Pharmaceutical and Biomedical Analysis, vol. 42, n. 3, p. 354-361, 2006. 